\title{
PARA PENSAR O APRENDERENSINAR DANÇA A PARTIR DE UMA PERSPECTIVA DECOLONIAL
}

Neila Cristina Baldi ${ }^{\mathrm{i}}$

\begin{abstract}
Resumo: Este artigo apresenta uma proposta para o aprenderensinar dança a partir de uma perspectiva decolonial. O texto sugere que uma prática pedagógica decolonial em dança pode surgir a partir dos pressupostos epistemológicos da Educação Somática, do Construtivismo PósPiagetiano e da Autobiografia. Esses saberes têm em comum princípios como a processualidade e a valorização da singularidade dxs sujeitxs. As práticas educativas em dança têm se pautado por pensamentos coloniais, tanto do ponto de vista da proposição de que estéticas seriam fundamentais quanto da perspectiva metodológica, com predominância de modos de praticar a dança e de saberes específicos a serem vivenciados. Neste sentido, a proposição de uma prática pedagógica decolonial na dança vai contra o status quo.
\end{abstract}

Palavras-chave: Pedagogias da dança; Educação Somática; Construtivismo Pós-Piagetiano; Autobiografia; Pedagogias decoloniais.

\section{PARA PIENSAR EL APRENDERENSEÑAR DANZA DESDE UNA PERSPECTIVA DECOLONIAL}

Resumen: Este texto presenta una propuesta para aprenderenseñar danza desde una perspectiva decolonial. $\mathrm{O}$ texto sugiere que una práctica pedagógica decolonial en danza pude surgir desde los presupuestos epistemológicos de la Educación Somática, del Constructivismo PostPiagetiano y de la Autobiografía. Eses saberes tienen en común principios como el proceso y la valorización de la singularidad dxs sujetxs. Las prácticas educativas en danza tienen se pautado por pensamientos coloniales, tanto do punto de vista de la proposición de que estéticas serían fundamentales cuanto de la perspectiva metodológica, con predominancia de modos de practicar a danza y de saberes específicos a ser vivenciados. En este sentido, la proposición de una práctica pedagógica decolonial en danza se va contra el status quo.

Palabras-clave: Pedagogías de la danza; Educación Somática; Constructivismo PostPiagetiano; Autobiografía; Pedagogías decoloniales.

\section{Introdução}

Se a Educação como um todo tem se pautado, na maior parte das vezes, a partir de uma perspectiva colonialista, a educação em dança não é diferente. Boaventura de Sousa Santos (2002) chama de monocultura do saber os saberes hegemônicos que, ao longo dos séculos, se 
constituem na Educação. Na dança a monocultura se dá tanto no modo como a mesma é ensinada, bem como no conteúdo - aqui refiro-me às técnicas codificadas e aos saberes técnicos. Ainda há o privilégio de uma estética de dança - o balé clássico, principalmente bem como o de um modelo de ensino - o da Pedagogia Tradicional.

Isabel Marques (2007) diz que: O balé clássico hoje volta a ser visto como base para o aprendizado em dança e que, com isso, assume-se que este preparará o bailarino para qualquer coisa (VAN DYKE apud MARQUES, 2007, p 67). Para ela, a visão de uma 'necessidade' do balé clássico talvez seja uma resposta à dança mais livre dos anos 1960 e 1970. Ou seja, o ensino-aprendizagem em dança volta-se novamente para a arte em si, suas técnicas e códigos (MARQUES, 2007, p. 70). Isso significa que quando não há a primazia de uma técnica codificada - como o balé clássico - há uma tendência à valorização de exercícios técnicos.

Por outro lado, Rosana Olarte (2007) lembra que em nove de dez aulas de dança, de diferentes técnicas, xs professorxs falam enquanto executam o movimento ou o explicam verbalmente, se referindo ao que é e não ao como. Ou seja, ao produto - visão típica da Pedagogia Tradicional - e não ao processo. Enquanto Anu Söot e Ele Viskus (2013) afirmam que xs alunxs aprendem imitando vocabulários específicos de movimento modelados por um professor especialista ${ }^{\text {ii }}$. (SÖOT; VISKUS, 2013, p. 1192). Na concepção de ensino tradicional:

[...] o professor é a autoridade e a única fonte de conhecimento reconhecida. Todos os alunos olham para o professor e para o espelho e o professor frequentemente olha para o espelho também, vendo os alunos através de suas imagens refletidas. [...] O professor diz e mostra aos alunos o quê e, em alguns casos, como fazer os exercícios propostos. (STINSON, 1995, p. 78-79)

Neste modo de ensinar - que não é entendido do ponto de vista de aprenderensinariii está implícita ainda outra colonialidade: a da separação corpo e mente. É frequente entre muitxs professorxs de dança a visão de que o corpo é um instrumento - a partir do pensamento cartesiano - e não de que somos corpo. Quando se parte da premissa desta separação e não da integração corpomente, as aulas de dança acabam por se pautar em:

[...] uma atividade mecânica que valoriza o virtuosismo quantitativo - o quão alto, quão rápido, quão grande. Exercícios e seqüências são repetidas inúmeras vezes até se tornarem virtualmente automáticas. Cada parte do corpo pode ser trabalhada isoladamente, "orquestrada" com outras partes. Acreditase, predominantemente, que o corpo de alguma forma saberá como integrarse e que as diferenças nos níveis de aprendizagem individual encontrarão resoluções. (WOODRUFF, 1999, p. 32) 
Neste tipo de educação em dança há ainda a primazia da individualidade - tão cara à modernidade. Apesar de fazerem aulas juntxs, o pensamento é de que xs estudantes não aprendem juntxs, mas de que cada pessoa tem a sua aprendizagem, individual, progressiva. São raras as proposições, a partir de uma Pedagogia Tradicional, de trabalhos coletivos, por exemplo. É lógico que cada pessoa tem o seu caminho individual e singular, mas não aprendemos sozinhxs, aprendemos, como diria Paulo Freire (1987), em comunhão.

Ou seja, pelo exposto, a colonialidade em dança se dá em várias frentes. Há um tipo de dança pensado como universal - o balé clássico, considerado ainda por muitas pessoas como técnica de base - bem como um modo de transmissão deste saber, centrando-se nxs professorxs como detentorxs do conhecimento, cujo modelo de movimento deve ser repetido e aprimorado, bem como uma tendência à valorização da individualidade. Além disso, os saberes privilegiados nas aulas de dança são aqueles considerados como técnicos: eixos, giros, saltos, posturas etc. Quais são os saberes dxs alunxs? O que elxs têm a contribuir para as aulas de dança? Como os saberes de $\mathrm{x}$ se relacionam com os saberes dxs demais?

Boaventura de Sousa Santos (2002, p. 238) nos lembra de que a experiência social em todo o mundo é muito mais ampla e variada do que o que a tradição científica ou filosófica ocidental conhece e considera importante. No entanto, segundo ele, há uma racionalidade vigente (razão metonímica) que reivindica ser a única forma de racionalidade. É visível, portanto, hoje, que na educação em dança há a predominância de um tipo de saber.

Pensar a aula de dança em uma perspectiva decolonial começa, na minha avaliação, em não partir do ponto de vista do ensino, mas do aprenderensinar. Os processos de aprender e de ensinar são indissociados, estamos constantemente vivendo as duas faces ou trocando-as, pois como afirmava Paulo Freire (1996) não há docência sem discência. Professorxs não apenas ensinam, também aprendem enquanto ensinam. Considerar esta perspectiva já é retirar dxs professorxs o lugar de detentorxs do saber. É sair da verticalidade das relações - entre professorxs e estudantes, mas também entre xs próprixs alunxs - para outras formas de se relacionar, mais complexas.

Este texto pretende discutir uma proposta para o aprenderensinar dança a partir de uma perspectiva decolonial, tendo como pressupostos epistemológicos a Educação Somática, o Construtivismo Pós-Piagetiano e a Autobiografia. A ideia é apresentar a convergência 
epistemológica entre estes saberes e de como, a partir dos seus princípios, o aprenderensinar dança pode ser decolonial.

Para compreender este tipo de pensamento pedagógico como decolonial parto de Adolfo Achinte (2013, p. 452) de que: Entendemos a decolonialidade como o processo por meio do qual re-conhecemos outras histórias, trajetórias e formas de ser e estar no mundo, distintas da lógica racional do capitalismo contemporâneo como expressão corporal (JAMESON, 1995; ZIZEK, 1998) ${ }^{\text {iv }}$. E apoio-me também em Catherine Walsh (2013, p. 67), de que a decolonialidade não é uma teoria a seguir, mas um projeto a assumir. É um projeto de ação para pedagogicamente andar. ${ }^{\mathrm{v}}$

\section{Educação Somática: a integração corpomente}

A Educação Somática nasceu no início do século XX e compreende trabalhos corporais a partir do entendimento de integração corpo e mente. No início do século passado, os chamados reformadores do movimento iniciaram pesquisas corporais - muitas delas voltadas para a autocura - que partiam da premissa de que nenhum ser humano é igual ao outro e de que estas diferenças deveriam ser respeitadas e mantida (STRAZZACAPPA, 2009, p. 49). Aqui já é explícita uma visão decolonial, antes mesmo de, do ponto de vista espaço-temporal, se falar em decolonialidade. O pensamento somático vai ao encontro, portanto, da(s) pedagogia(s) decolonial(is) $)^{\text {vi }}$, uma vez que:

Esta pedagogia é uma forma de conhecer e fazer encarnada em corpos individuais e coletivos, encarnada nas experiências subjetivas, corpóreas e emocionais das mulheres que lutam. Desta maneira, integram o que a modernidade dicotomizou e hierarquizou: corpo e mente, emoção e razão, individualidade e coletividade se articulam para a partir dali aprender e não só modificar os discursos e prática que fazem e desfazem os corpos. (ESPINOSA et al, 2013, p. 417)

É importante ressaltar que, apesar de se referenciar à subjetividade de cada pessoa, a Educação Somática não trabalha apenas em uma perspectiva individualista. Pelo contrário, há relação entre o sujeito e o meio - incluindo as outras pessoas.

De acordo com Martha Eddy (2009), havia um ambiente favorável ao desenvolvimento das técnicas e métodos somáticos, uma vez que na virada do século XIX para o XX, o mundo vivia movimentos como o existencialismo e a fenomenologia; os estudos de Sigmund Freud, 
Carl Jung e Wilhelm Reich, na psicologia; Heinrich Jacoby e John Dewey na educação; e Edmond Jacobson na área médica. Para a autora, François Delsarte (1811-1871), Emile Jacques-Dalcroze (1865-1950), Rudolf Laban (1879-1958), Isadora Duncan (1878-1927) e Mary Wigman (1886-1973) prepararam o terreno para a Educação Somática, pois eram pessoas que estavam quebrando regras e reintroduzindo modelos não cartesianos ${ }^{\mathrm{viii}}$ (EDDY, 2009, p. $10)$.

Nos anos 1970, o filósofo Thomas Hanna viu características em comuns nestas práticas e nomeou-as como Educação Somática: O centro do campo da Somática é o soma - um processo integral e individual, que rege a sua própria existência contanto que tenha existência (HANNA, 1976, s.n.). Segundo ele, o soma é o corpo experienciado a partir dele mesmo. De acordo com Thomas Hanna (1977), são características da Educação Somática: autorregulação, autocorreção, automelhoria e autoconsciência.

Todas essas quatro características existem porque as técnicas e métodos somáticos partem do princípio de valorização da subjetividade, de privilegiar as sensações, perceber o processo, em uma constante observação de si e dx outrx. Além disso, segundo o Regroupement pour l'education somatique (R.E.S), a Educação Somática promove a responsabilidade individual, junto com a autonomia, a partir da experiência íntima e pessoal ${ }^{\text {ix }}$. As quatro características são integradas, uma vez que a tomada de consciência permite, por exemplo, a autorregulação, a autocorreção e a automelhoria. Será esta apropriação que provocará as mudanças no universo em que as ações estão se dando e, por consequência, como uma onda, manifestar-se-á em todos os seus confins (LIMA, 2010, p. 62). Ou seja, é perceptível, apesar de Thomas Hanna (1977) não ter elencado, que na Educação Somática, a integração não é só corpomente. Mas no todo e na própria teoria.

Segundo Sylvie Fortin (2002), desde a criação dos métodos e técnicas somáticos, no início do século passado, a Educação Somática já passou por cinco fases: o surgimento das técnicas e métodos, a disseminação dos mesmos - até meados dos anos 1970 -, o uso na terapia, psicologia e artes - entre 1970 e 1990 -, e a partir do final do século passado, o desenvolvimento de práticas idiossincráticas e o crescimento de uma comunidade de pesquisa.

Sylvie Fortin (2002, p. 130) afirma que: A transformação é um aspecto integral da somática. O campo da somática está mudando continuamente ao mesmo tempo em que seus praticantes desenvolvem caminhos únicos ${ }^{\mathrm{x}}$. Ou seja, aqueles que trabalham com a Educação 
Somática hoje não necessariamente se fecham em um método ou técnica, mas mesclam conhecimentos de modo que os trabalhos se distinguem.

O mundo da dança começou a se aproximar da Educação Somática a partir dos anos 1970. Para Eloisa Domenici (2010), o encontro da dança com a Educação Somática proporcionou uma mudança na maneira de se pensar o corpo, provocando uma busca pelo respeito aos limites anatômicos, além de estimular a exploração de novos movimentos e possibilitar o questionamento de modelos e concepções sobre o treinamento corporal. Influenciou, inclusive, o modo de se aprenderensinar dança.

Desta forma, muito do que hoje a dança produz com a Educação Somática parte muito mais de princípios gerais da Educação Somática do que de técnicas e métodos específicos. Para além disso, atualmente pensadorxs da dança falam em Pedagogia Somática. José Antônio Lima (2010, p. 62) pergunta:

Qual seria então a especificidade da educação somática? Acredito particularmente que esta especificidade esteja relacionada ao projeto de apropriação pelo indivíduo da ação que lhe é proposta. Será esta apropriação que provocará as mudanças no universo em que as ações estão se dando e, por consequência, como uma onda, manifestar-se-á em todos os seus confins. [...] A intenção é projetar a ideia de que "somática" é um conceito relacionado ao modo de se fazer e não a uma técnica específica. A educação somática não é uma técnica, é, antes, uma proposta de um modo particular de como aprender, de como trocar conhecimento, um método, uma proposta pedagógica, e, como ação pedagógica ímpar, insere-se nos processos de transformação do indivíduo e, por consequência, da sociedade.

Ele acrescenta que, desta forma: haveria um modo de modificando-se uma técnica, a princípio não somática, ou buscando-se nela os princípios originais da somática encontrar-se um modo de entendê-la e praticá-la somaticamente (LIMA, 2010, p. 62, grifos do autor).

Há outras pessoas também pensando na existência de uma Pedagogia Somática, como Anu Söot e Ele Viskus (2013), a partir de Enghauser (2007 apud SÖOT; VISKUS, 2013, p. 8889) que elencam como princípios metodológicos presentes nesta pedagogia a autopercepção e não um aprendizado imitativo, comum em várias aulas de dança, que partem da cópia e repetição do movimento - a experimentação, a anatomia experiencial, um ambiente não autoritário, a resolução criativa de problemas e o fomento à voz criativa dxs alunxs.

Considerar a Educação Somática como pedagogia é se apropriar de seus pressupostos epistemológicos, de seus princípios e procedimentos e levá-los para a sala de aula. Neste sentido, 
Yvan Joly (2002) elenca uma série de procedimentos somáticos, segundo ele, estes vão desde uma descoberta guiada até a exploração de movimentos; uma variação no uso do espaço e/ou na interiorização do movimento, ao uso do solo ou da verticalidade, do apoio de objetos ou não. Afirma ainda que se pode incluir desde a formulação verbal da experiência, a utilização de imagens ou a comunicação pelo toque.

Os princípios da Educação Somática vão ao encontro do pensamento de Walter Mignolo e Rolando Vásquez (2017, p. 499) de que: Quando se percebe o mundo a partir do corpo, o mundo já não é um objeto à mão, mas que faz parte do mundo, nosso corpo e nosso futuro é mundo ${ }^{\mathrm{xi}}$. Esta perspectiva é um contraponto à modernidade/colonialidade que olhava o mundo como um objeto e o sujeito como um ser desencarnado, abstrato.

\section{Construtivismo Pós-Piagetiano: saberes pessoais e relacionais}

O chamado Construtivismo Pós-Piagetiano abrange tanto a teoria do suíço Jean Piaget (1896-1980) quanto seus desdobramentos posteriores. Segundo Isabelle Sanchis e Miguel Mahfoud (2010), Piaget é considerado o primeiro pesquisador, nas Ciências Humanas, a utilizar o termo Construtivismo ${ }^{\text {xii }}$, quando formulou a teoria da Epistemologia Genética. E mesmo antes dele morrer o termo pós era utilizado, uma vez que a essência do Construtivismo era ser continuado, modificado (GROSSI, 1993):

O termo hoje designa um conjunto teórico e de práticas que abrange a obra de muitos autores e desdobramentos práticos diversificados. Piaget, apesar de ter alguns escritos sobre educação, não foi e não pretendeu ser pedagogo, e não teve, portanto, como interesse, a realização de projetos ou métodos pedagógicos. No entanto, verifica-se que grande parte da produção que tem como fundamento o construtivismo refere-se à educação, e, mais especificamente, à educação formal. Sendo assim, os métodos pedagógicos hoje ditos construtivistas são construções baseadas na teoria formulada por Piaget, principalmente sobre o desenvolvimento infantil (ou em algum tema contido nela) e/ou em autores que desenvolveram suas pesquisas na mesma linha. (SANCHIS; MAHFOUD, 2010, p. 19-20)

De acordo com Mary Ann Pulaski (1986) a teoria de Piaget está calcada em três pilares: equilibração, experiência e transmissão social. Fernando Becker (2011) acrescenta a maturação. Conhecer, para Piaget, tem o sentido de: organizar, estruturar e explicar, porém, a partir do vivido (do experenciado) (RAMOZZI-CHIAROTINNO, 1988, p. 3). Ou seja, no 
Construtivismo Pós-Piagetiano, aquelx que aprende é um ser ativo, diferente da Pedagogia Tradicional, que vê xs alunxs como seres passivos. Tanto na Educação Somática quanto na Autobiografia, saberes epistemológicos também usados aqui na proposição de uma pedagogia decolonial para a dança, há prevalência deste tipo de pessoa.

Aqui nesta definição de como se dá o conhecimento para o teórico suíço, temos dois de seus pilares: a equilibração e a experiência. Para Piaget, o conhecimento é construído a partir de um jogo de forças de equilíbrio-desequilíbrio, ou seja, a chamada equilibração se dá a partir da assimilação e da acomodação. A assimilação é o que provoca o desequilíbrio e a acomodação, o que permite o equilíbrio. A assimilação nunca é pura, pois ao incorporar os novos elementos, a inteligência modifica os esquemas de pensamento. Por outro lado, as coisas nunca são conhecidas em si mesmas, uma vez que a acomodação só é possível em função do processo inverso de assimilação. Ora, esses dois aspectos do pensamento são indissociáveis: é adaptando-se às coisas que o pensamento se organiza e é organizando-se que estrutura as coisas (PIAGET, 1987, p. 18-19). E todo esse processo, segundo ele, é ativo, e se dá pela experiência, pela ação - mesmo que reflexiva.

Na teoria de Piaget, a transmissão social também é importante. O Construtivismo apresenta, por defender uma construção possibilitada pela interação, um modo de existir relacional (SANCHIS; MAHFOUD, 2007, p. 170). E isso tem relação com a Educação Somática. Ou seja, falamos da singularidade do sujeito, mas em relação com x outrx.

Para Piaget, quando, por exemplo, uma criança ouve afirmações contraditórias ou desafiadoras, ela vive um desequilíbrio: o chamado conflito cognitivo. Na busca pela solução do problema, a criança pode chegar a um equilíbrio momentâneo - provisório para aquele conceito - considerado, posteriormente, um erro. Ou seja, ela aprende com seus erros. Emília Ferreiro e Ana Teberosky (1999, p. 33) dizem que:

[...] Na teoria de Piaget, o conhecimento objetivo aparece como uma aquisição, e não como um dado inicial. $\mathrm{O}$ caminho em direção a este conhecimento objetivo não é linear: não nos aproximamos dele passo a passo, juntando peças de conhecimento umas sobre as outras, mas sim através de grandes reestruturações globais, algumas das quais são "errôneas" (no que se refere ao ponto final); porém "construtivas" (na medida em que permitem aceder a ele). Essa noção de erros construtivos é essencial.

Sobre esta questão, Fernando Becker (2011, p. 221) diz que: 
Cada passo depende, simultaneamente, do sujeito e do meio. Se o sujeito não encarar o desafio e esforçar-se para realizar uma acomodação (transformação nele mesmo) (PIAGET, [1936], 1978, Introdução), e o meio não oferecer condições objetivas para isso acontecer, o desenvolvimento não avançará, ou avançará aquém ou muito aquém das possibilidades. A noção de desenvolvimento cognitivo, em Piaget, tem um forte componente histórico e social. Ignorar isso é desvirtuar o significado essencial do conceito central da Epistemologia Genética: a interação.

O autor acrescenta que sem maturação não há desenvolvimento, mas o desenvolvimento vai além dela. Segundo ele, a maturação está presente em cada transformação que ocorre no desenvolvimento, mas se o desenvolvimento se reduzisse a ela, todas as aquisições deveriam ocorrer mais ou menos na mesma idade em todas as pessoas (BECKER, 2011, p. 218). E isso não ocorre, a aprendizagem depende, também, do meio social.

Os estudos de Piaget não propunham, no entanto, fazeres pedagógicos. Mas é inegável que seus resultados são da maior relevância para a educação, precisamente porque redefinem a noção de aprendizagem, noção que nenhum pedagogo pode evitar (FERREIRO, 2001, p. 98). A partir de seus estudos, houve quem propusesse uma aula construtivista:

Nos anos 1990, havia quem chamasse o Construtivismo (Pós-Piagetiano ou não) de tendência pedagógica. Tanto que Lauro de Oliveira Lima, um dos estudiosos da teoria de Piaget no Brasil, criou, no Rio de Janeiro, uma "escola construtivista". Atualmente é comum muitas escolas terem como pensamento pedagógico o Construtivismo Sócio-Interacionista (que, neste caso, une a teoria de Piaget com a de Vygotsky). (BALDI, 2017, p. 220)

Aqui a proposta é pensar nos pressupostos de sua teoria e, a partir deles, construir procedimentos e estratégias que valorizem a construção do conhecimento, que permitam tanto o aprender a aprender quanto o aprender a desaprender. É comum, para quem parte desses pressupostos, o trabalho em grupo, por exemplo, uma vez que o conhecimento é singular, mas se dá em relação com xs outrxs. Na dança, é comum a aprendizagem a partir do modelo de movimento; aqui a ideia é propor, por exemplo, desafios corporais, explorações de movimento, de modo que $\mathrm{x}$ alunx não tenha necessariamente um modelo a seguir, mas que possa construir sua dança, seus movimentos, mesmo quando se parta de uma dança codificada - como o balé clássico. Neste caso, a exploração pode partir do princípio do movimento: o que é o plié, se não um dobrar? Então eu posso explorar o dobrar, em diversos segmentos - pernas, braços etc. entendê-lo cinestesicamente para chegar ao dobrar dos joelhos e então, ao plié. A ideia é, a 
partir dos pressupostos do Construtivismo Pós-Piagetiano propor um tipo de aula que movimento codificado não seja dado a priori.

Pensar pedagogicamente a partir dos pressupostos do Construtivismo Pós-Piagetiano nos permite compreendê-lo decolonialmente, como o proposto por Espinosa et al (2013, p. 414) quando se refere às práticas pedagógicas feministas:

[...] esta pedagogia torna possível a produção de outro tipo de conhecimento, muito mais próximo a formas de aprendizagem e de produção de verdade assentadas na cotidianidade e nas lógicas comunitárias e organizativas assentadas na valorização da experiência vivida. [...] Se parte da possibilidade de construir coletivamente a partir da troca de saberes e conhecimentos que implica em reconhecer que todas e todos somos sabedores e produtores de conhecimento. ${ }^{\text {xiii }}$ (grifos meus)

\section{Autobiografia}

Autobiografia foi constituída na segunda metade do século passado e abrange tanto histórias de vida, quanto narrativas de si, autobiografias, biografias educativas, entre outras áreas, diferenciando-se conforme os procedimentos de pesquisa. Por isso, de acordo com Tânia Fortuna (2012, p. 169) é tão fácil perder-se em imprecisões conceituais quanto é fácil dispersar-se em preciosismos terminológicos. Neste sentido, aqui o conceito de Autobiografia é a de saberes que incluem pesquisas que analisam como os indivíduos veem e representam a sua existência (FORTUNA, 2012, p. 167).

$\mathrm{Na}$ Educação, a pesquisa autobiográfica tem sido usada, sobretudo, na investigação sobre a formação docente. Mas há autorxs que enxergam a Autobiografia tanto como um método de pesquisa, quanto pedagógico. De pesquisa porque o pesquisador se utiliza dos dados autobiográficos; e pedagógico porque escrever sobre si é conhecer-se e, portanto, é autoformador. Interessa, neste artigo, o entendimento nestes dois sentidos, uma vez que a proposta de uma pedagogia decolonial para a dança parte, entre seus procedimentos, da pesquisa do movimento. Ou seja, falo de alunxs que são também pesquisadorxs. São pesquisadorxs do movimento, em movimento, e de suas autobiografias, bem como as próprias podem servir de pesquisa de movimento.

Vale salientar também que a Autobiografia, como método investigativo e pedagógico, não precisa se restringir às escritas no papel: 
[...] Como se sabe, a autobiografia refere-se às várias formas de escrita de si e a grafia é tudo isso que deixa um traço, um signo. Assim, de acordo com Staccioli, as histórias de vida podem ser "traçadas com a pena ou a palavra, através de expressão corpórea, da música, da dança, do jogo, das imagens", sendo que "os signos traçados podem ser encorpados ou etéreos, bidimensionais ou tridimensionais, duradouros ou fugazes" (STACCIOLI, 2005, p. 58, tradução minha). (FORTUNA, 2012, p. 182)

Neste sentido, um conceito importante de trazer para esta discussão de Autobiografia como pressuposto epistemológico para uma pedagogia decolonial na dança é o de corpografias. Cada um traz escrito, em seu corpo, uma memória de vida, uma história, um contexto familiar (VIANNA; CASTILHO, 2002, p. 24). Ou seja, nosso corpo é inscrito pelos acontecimentos que nos afetam. Mas, ao mesmo tempo, também inscreve e escreve. Desta forma, chamo de corpografias $^{\mathrm{xiv}}$ as (es)(ins)critas do corpo. Em última instância pode-se dizer que, ao trabalhar com as memórias, as narrativas e as escritas - do papel ao movimento - a Autobiografia acaba por trabalhar, então, com as corpografias.

E o que nos dizem essas corpografias? Segundo Valeska Oliveira (2011, p. 125-126):

Os registros trazidos na escrita pelo trabalho da memória e também pelo esquecimento trazem à tona os processos formativos significativos e as aprendizagens neles construídas. Nas narrativas, percebemos os deslocamentos de sentidos numa trajetória pessoal e profissional, bem como os movimentos identificatórios.

A Autobiografia - em seus mais diversos procedimentos - é considerada, portanto, um processo autoformativo. Marie Christine Josso (2004) afirma que as experiências revividas pelos diversos métodos de pesquisa da Autobiografia não apenas contam o que a vida ensinou, mas o que se aprendeu. Mas ela ressalva que às vezes é difícil compreender que esta metodologia favorece um conjunto de aprendizagens que vão muito além de um processo de conhecimento de si no registro psicológico (JOSSO, 2004, p. 171). Importante esta colocação, para que não se pense que processos educativos em dança, a partir de procedimentos da Autobiografia, sejam terapia.

Temos evidente na Autobiografia a singularidade da pessoa, pois o exercício de desvelamento que caracteriza a pesquisa autobiográfica fundamenta-se na memória. A memória assinala a nossa singularidade, direcionando as possibilidades de ser e fazer (CUNHA, 2012, p. 101). Singularidade que encontramos também na Educação Somática e no 
Construtivismo Pós-Piagetiano, como discutido anteriormente. Mas também uma singularidade relacional, plural, uma vez que:

[...] as histórias que contamos sobre nós mesmos e que, segundo alguns, nós dirigimos a outros, longe de nos jogar numa intimidade inacessível, têm por efeito articular nosso espaço-tempo individual ao espaço-tempo social. (DELORY-MOMBERGER, 2012, p. 75)

Do ponto de vista metodológico, os procedimentos tanto de pesquisa quanto pedagógicos da Autobiografia são inúmeros e distintos: escritas de si, por meio de diários e inventários pessoais, portfólios, ateliês etc. Em todos eles a chamada reflexão na ação está presente. São escritas - mesmo aquelas em movimento - que nos permitem refletir sobre o vivido e, mais que isso, atuar sobre. As descobertas autoformativas da Autobiografia permitem autorregulações, autocorreções etc. - para usar termos da Educação Somática, por exemplo. A Autobiografia é autoformativa exatamente porque nos transformamos a partir desses processos e, muitas vezes, transformamos também coletivamente. Assim, do ponto de vista das pedagogias decoloniais, não estamos apenas mudando os conteúdos das aulas de dança trazendo, por exemplo, as histórias de vidas de nossxs estudantes - mas estamos mudando a concepção do que seja conhecer, quem e para quem se produz o saber, refletindo sobre as problemáticas que afetam a vida onde estamos (PALERMO, 2014).

\section{Confluências epistemológicas}

Boaventura de Sousa Santos (2009, p. 45) afirma que o pensamento pós-abissal tem como premissa a ideia da diversidade epistemológica do mundo, o reconhecimento da existência de uma pluralidade de formas de conhecimento além do conhecimento científico (grifo meu). A proposta aqui apresentada traz esta perspectiva, ao unir três saberes epistemológicos que enxergam o conhecimento para além da razão metonímica (SANTOS, 2002). Vai ao encontro também do pensamento de Boaventura de Sousa Santos (2002) de ecologia de saberes: o diálogo entre os saberes científicos ou humanísticos e os saberes leigos (populares, tradicionais, indígenas, africanos, etc.). Nesta proposta, os saberes não técnicos da dança são também valorizados, bem como aqueles oriundos dxs alunxs. 
Enxergo que a Autobiografia, a Educação Somática e o Construtivismo Pós-Piagetiano - apesar de terem surgido em épocas distintas - têm confluências epistemológicas. Isabelle Sanchis e Miguel Mahfoud (2010, p. 26) dizem que no Construtivismo Pós-Piagetiano não se pensa apenas em aprendizagem formal, mas em um processo de constituição do sujeito, que aprende desde que nasce e até sua morte, na medida em que apreende e compreende o mundo que o cerca. Ora, a processualidade é uma característica tanto da Educação Somática quanto da Autobiografia. Além disso, pelo exposto, ambos enxergam os saberes para além da razão metonímica como formativos; e entendem o conhecimento a partir da autoformação - com interação explícita no caso do Construtivismo Pós-Piagetiano e na Educação Somática e implícita na Autobiografia. As narrativas ou escritas de si, proporcionadas pela Autobiografia, permitem que pensemos: nas marcas produzidas - o que fizeram conosco, para então pensarmos no que podemos fazer conosco a partir de agora (OLIVEIRA, 2011, p. 132).

Sylvie Fortin e Warnick Long (2005) também veem intersecções entre a Educação Somática e o Construtivismo Pós-Piagetiano. Na avaliação delxs, a abordagem somática que utilizam - Método Feldenkrais - está em acordo com a orientação epistemológica construtivista, uma vez que o ponto de partida é a singularidade da pessoa e a experiência sensorial de cada alunx. Pelo exposto, a singularidade do ser está presente na Educação Somática, na Autobiografia e no Construtivismo Pós-Piagetiano. No caso da Autobiografia, a experiência sensorial é validada quando as narrativas se dão por práticas corporais.

O conceito de autorregulação - Fernando Becker (2011) entende a equilibração proposta no Construtivismo Pós-Piagetiano como um processo de autorregulação, de retroalimentação (feedback e feedforward) - é outra confluência e muito cara às pedagogias decoloniais, uma vez que a decolonização é considerada uma desaprendizagem, um desaprender do que foi imposto para reaprender, são pedagogias que provocam aprendizagens, desaprendizagens e aprendizagens (WALSH, 2013). Além disso, ao dar ênfase, dentro do Construtivismo PósPiagetiano aos aspectos estruturantes ou processuais do conhecimento e de compreensão da realidade, na medida em que se dão conjuntamente com a construção do próprio sujeito que conhece (SANCHIS; MAHFOUD, 2010, p. 24), Becker acaba por aproximar Piaget a Paulo Freire, na medida em que o conhecimento é ação e transformação. Seu entendimento, com o qual eu coaduno, acaba por me remeter à Aura Cumes (2017) que nos pergunta para que serve o conhecimento se não se construir questionando a normalização dos poderes que nos envolvem. 


\section{Aprenderensinar dança na perspectiva decolonial}

Considerar uma pedagogia decolonial para a dança é, portanto, pensar em aprenderensinar dança e não apenas em ensino. Pensar somaticamente, com todo o ser, e não apenas do ponto de vista racional, intelectual, de reflexão sobre esse fato. Ou seja, é sair de uma visão muitas vezes vertical na vivência em dança para uma perspectiva multidirecional, já que, como bem falava Paulo Freire (1987, p. 167) aprendemosensinamos em comunhão, na medida em que "ninguém desvela o mundo a outro", mas que nos tornemos "sujeitos do ato de desvelar".

Neste sentido, para uma pedagogia decolonial para a dança é preciso sair da lógica binária: corpo-mente, sair do entendimento de que o corpo é um instrumento e de que os saberes da dança são apenas e tão somente os chamados saberes técnicos. Walter Mignolo e Rolando Vásquez (2017, p. 496) dizem que:

As disciplinas privilegiam a formação e escolarização disciplinaria sobre a educação das pessoas (professores e estudantes). A pedagogia decolonial vai em outra direção. Enfatiza a emoção sobre a razão, a história pessoal sobre os princípios e métodos disciplinares $^{\mathrm{xv}}$

Neste sentido, pensar - e aqui o verbo tem sido repetido propositalmente - em uma pedagogia decolonial para a dança pode ser, então, pensar em uma pedagogia que se aporte em procedimentos vindos do Construtivismo Pós-Piagetiano, da Educação Somática e da Autobiografia ou de procedimentos construídos a partir dos seus pressupostos epistemológicos. Aqui, a proposta não é uma receita de bolo - porque, do contrário, estaria sendo contraditória com o próprio pensamento decolonial - mas apontar alguns caminhos possíveis.

Como provocamos desaprendizagens e novas aprendizagens em nossxs estudantes de dança? São diversos os caminhos possíveis. Independente dos procedimentos utilizados, sugiro sempre que xs estudantes tenham um diário de bordo - caderno em que anotam percepções, sensações, dúvidas etc., uma vez que:

[...] essas anotações são um exercício de si de duplo uso, identicamente aos hypomnémata de que fala Foucault: uso para si mesmo, como forma de assimilação e retenção do que foi vivido em cada encontro, e uso pelo outro no caso, pela pesquisa e por seus possíveis leitores [...]. (ABRAHÃO, 2012, p. 188) 
Ora, a decolonialidade pressupõe uma visão crítica sobre seu processo de aprenderensinar. Deste ponto de vista, os diários de bordo servem como momentos de reflexão. Deles emergem questões como a percepção de tendências de movimento, preferências estéticas, entre outras.

Do ponto de vista da Educação Somática, um procedimento comum é fechar os olhos para sentir como o movimento está sendo realizado. A partir disso, pode-se, por exemplo, perceber o caminho do movimento: começa pelo quadril, pelo pé, por onde? Perceber o caminho do movimento permite que $\mathrm{x}$ alunx possa variar a sua iniciação, uma vez que: Uma mesma ação pode ser realizada de maneiras totalmente distintas, dependendo de qual parte inicia e qual(is) parte(s) dá(dão) continuidade ao movimento (FERNANDES, 2006, p. 67). Com isso, $\mathrm{x}$ estudante percebe o que essa alteração provoca não apenas em termos anatômicos mas também em termos expressivos.

Outro procedimento comum na Educação Somática que utilizo nas aulas de dança - e que poderia ter nascido dos pressupostos do Construtivismo Pós-Piagetiano, que incentiva o trabalho em grupo - é o de xs colegas se observarem e darem feedback. Muitxs estudantes relatam que ao olhar x colega, aprendem também e percebem o que em si está sendo feito de forma anatomicamente disfuncional, ou sem limpeza de movimento etc.

No que tange ao Construtivismo Pós-Piagetiano, xs professorxs podem propor a pesquisa de movimento para a chegada a um código específico (ou não). Uma estratégia que uso em sala de aula é o de pesquisar verbos de ação (dobrar, estender, girar etc.) em diversas partes do corpo. Como é dobrar as mãos, saltar os ombros, deslizar o quadril? Nesta pesquisa com verbos pode-se chegar a movimentos inusitados e não codificados, mas pode-se chegar a códigos específicos, como um plié do balé clássico (dobrar os joelhos, na pesquisa de movimento, por exemplo). Este tipo de procedimento:

[...] permite a emergência de uma dança própria e não a reprodução de movimentos já codificados (vindos de técnicas como o balé clássico, o jazz, a dança moderna etc.). [...] Muitas vezes, o(a) aluno(a) de dança acredita que dançar seja apenas e tão somente produzir movimentos codificados e não enxerga dança em outros movimentos - considera que o que não é codificado não é dança - e, por vezes, não acredita que possa produzir sua dança. (BALDI, 2017, p. 49-50)

Pensando a partir da Autobiografia, as narrativas escritas e dançantes são estratégias metodológicas para aprenderensinar dança. Refiro-me a narrativas escritas os inventários 
pessoais, texto escrito no papel no qual x estudante conta sobre sua vida, a partir da pergunta: como eu me tornei o que eu sou. Escrever sobre si permite, do ponto de vista decolonial, revisitar nossas interpretações do mundo e a ordem instituída através do exercício de rastrear os processos mediante os quais foram impostos determinados sentidos do mundo, enquanto outros têm sido constantemente descartados ou invisibilizados ${ }^{\mathrm{xvi}}$ (ESPINOSA et al, 2013, p. 412). A ideia aqui é uma primeira memória, escrita, para uma posterior memória em movimento. Ou seja, x estudante escreve seu inventário pessoal, posteriormente - de preferência em outro dia, para não ser influenciadx pela escrita - realiza a Vivência Rememorativa: que começa por um momento de "esvaziar-se", baseado na meditação ativa de Osho ${ }^{x v i i}$. Depois, cada x escolhe um lugar na sala e se deita. Aos poucos, vou conduzindo a rememoração, por fases de vida. Durante a vivência, x estudante pode mover-se, escrever, realizar o que aquela memória está lhe pedindo. As anotações e percepções dessa vivência serão confrontadas com o inventário pessoal escrito de modo que este possa ser reescrito - ou não. A reescrita do inventário pessoal é importante, pois o que o adulto diz de sua história não é idêntico em todos os momentos de sua vida, nem em todos os contextos nos quais se exprime (DOMINICÉ, 2010, p. 88). Também podem fazer parte das anotações de seu diário de bordo.

Algo que acho importante é fazer a reflexão na ação: por que estou fazendo dança, o que do meu movimento tem relação com a minha história de vida, entre outras questões. Não podemos esquecer das nossas corpografias e que neste rememorar a vida vêm à tona. Muitas vezes nestes momentos é que emergem informações como as tendências de movimento começo mais por tal membro, busco mais movimentos leves etc. A tomada de consciência das nossas tendências nos permite buscar outras formas de nos movimentar, ampliando nosso repertório - e isso tendo tudo a ver também com a Educação Somática.

Outro procedimento interessante é a partir do uso de material pessoal, como brinquedos, cartas, fotografias etc. Para além da memória afetiva, o manuseio do objeto nos conduz a movimentações que trazem outras memórias cinestésicas, e assim sucessivamente (BALDI, 2017 , p. 50). Neste sentido, posso desde dançar a movimentação do objeto, como criar cenas usando o objeto, deixando-o que este estimule a movimentação ou até pesquisar movimentos a partir da escrita das cartas, de frases soltas, da história delas etc. Sherry Shapiro (1998, p. 36) diz que:

Por meio do processo crítico de refletir sobre experiências vividas, os estudantes são capacitados a interpretar as relações sociais e individuais que 
vivem, e podem começar a entender seu próprio poder de transformar e recriar essas relações e, consequentemente, seu próprio mundo. (grifo da autora)

Assim como os diários de bordo são imprescindíveis em minha prática docente, o espaço para criação também o é. Proponho, ao longo das aulas, diversos momentos em que xs estudantes são convidadxs a criar sequências coreográficas - em aulas tradicionais de dança este procedimento não é comum. São criações que partem desde de procedimentos vindos da Autobiografia até a partir de técnicas codificadas ou da pesquisa de movimento ou pesquisa anatômica. Neste sentido, a proposta aqui discutida coaduna com a ecologia dos saberes, uma vez que:

$\mathrm{Na}$ ecologia dos saberes cruzam-se conhecimentos e, portanto, também ignorâncias. Não existe uma unidade de conhecimento, como não existe uma unidade de ignorância. As formas de ignorância são tão heterogêneas e interdependentes quanto as formas de conhecimento. Dada esta interdependência, a aprendizagem de certos conhecimentos pode envolver o esquecimento de outros e, em última instância, a ignorância destes. Por outras palavras, na ecologia dos saberes a ignorância não é necessariamente um estado original ou ponto de partida. Pode ser um ponto de chegada. Pode ser o resultado do esquecimento ou desaprendizagem implícitos num processo de aprendizagem recíproca. (SANTOS, 2009, p. 47)

Outra mudança de postura diz respeito às relações em sala de aula. É comum nas classes de dança aquelxs que sabem mais ou que acham que sabem mais se colocarem à frente dxs demais. Assim como é comum x professor se colocar à frente. Trabalho em uma perspectiva de relações multidirecionais. Se aprendemos em comunhão, os grupos e as formações em roda são muito frequentes. Mas se necessárias as formações em fileiras, estimulo que variemos a frente, de modo que todxs possam passar pela experiência de estar à frente ou comandar o início de uma movimentação.

As proposições aqui apresentadas vão ao encontro da fala de Adolfo Achinte (2014, p. p. 168) de que a produção de conhecimento não é necessariamente um ato individual, assim como a academia não é o único lugar onde se produz conhecimento ${ }^{\mathrm{xviii}}$. 


\section{Considerações finais}

Preconizar uma pedagogia para aprenderensinar dança a partir da decolonialidade é propor novos paradigmas para a sua aprendizagem, uma vez que os processos pedagógicos têm se pautado no ensino, baseados sobretudo em práticas reprodutivas de movimentos, com saberes técnicos. Aqui a proposta é que, para além da técnica, a vida dxs estudantes também seja currículo e que de suas vivências surjam novos saberes. Nesta perspectiva, são saberes da dança os conteúdos propriamente desta arte, que dizem respeito aos seus elementos técnicos, mas também os conteúdos expressivos - muitas vezes não trabalhados em aulas de dança - e os saberes oriundos dxs estudantes, conhecimentos estes que podem dizer respeito diretamente à dança ou não. Ou seja, há conteúdos gerais e singulares. Além disso, há uma mudança paradigmática no que diz respeito à organização destes conteúdos, uma vez que há a valorização da singularidade de cada pessoa. Singularidade esta que permite a coletividade, que possibilita a emergência de diversas vozes, uma vez que:

Pensar a partir do local, a partir do pertencimento, é construir um lugar epistêmico que inclua as diferenças, que reconhece os silenciados, os discursos que falam em seu nome e que fazem do silêncio uma metáfora poética. (PALERMO, 2014, p. 137)

Darcy Ribeiro (2006, p. 57) dizia que não se formulou jamais, nem se poderá formular, um discurso definitivo e suscetível à aplicação universal ${ }^{\mathrm{xx}}$. $\mathrm{O}$ que quero dizer que a minha proposição é uma entre inúmeras que podem surgir do ponto de vista decolonial. Além disso, é uma visão minha de decolonialidade e de pressupostos que possam propor esta pedagogia decolonial para a dança - outras epistemologias podem ser usadas no mesmo sentido. Pensar decolonialmente é não querer contrapor um pensamento hegemônico com outro. Boaventura de Sousa Santos (2002, p. 278) afirma que: A possibilidade de um futuro melhor não está, assim, num futuro distante, mas na reinvenção do presente. Estou tentando propor esta reinvenção e acredito que as pedagogias da dança tendem muito a ganhar ao serem revistas, assim como a própria dança. 


\section{Referências}

ABRAHÃO, Maria Helena Menna Barreto (org). Dimensões epistemológicas e metodológicas da pesquisa (auto)biográfica: Tomo II. Natal: EDUFRN; Porto Alegre: EDIPUCRS;

Salvador: EDUNEB, 2012.

ACHINTE, Adolfo Albán. Pedagogías de la re-existencia. Artistas indígenas y afrocolombianos. In: WALSH, Catherine. Pedagogías decoloniales: práticas insurgentes de resistir, (re)existir y (re)vivier. Tomo I. Quito: Ediciones Abya-Yala, 2013.

BALDI, Neila. Es(ins)critas do corpo dançante: narrativas singulares e plurais. Revista Brasileira de Pesquisa (Auto)Biográfica, Salvador, v. 02, n. 04, p. 41-56, jan./abr. 2017.

BECHER, Fernando. Aprendizagem: reprodução, destino ou construção. In: MONTOYA, Adrían Oscar Dongo. SHIMIZU, Alessandra de Morais. MARÇAL, Vicente Eduardo Ribeiro. MOURA, Josana Ferreira Bassi. (org). Jean Piaget no século XXI: escritos de epistemologia e psicologia genéticas. São Paulo: Cultura Acadêmica; Marília: Oficina Universitária, 2011.

CUMES, Aura. CARIÑO, Carmen. CURIEL, Ochy. GARZÓN, María Tereza. MENDONZA, Bienvenida. OCHOA, Karina. LONDOÑO, Alejandra. Pensar, sentir y hacer pedagogías feministas descoloniales: Diálogos y puntadas. In: WALSH, Catherine. Pedagogías decoloniales: práticas insurgentes de resistir, (re)existir y (re)vivier. Tomo II. Quito: Ediciones Abya-Yala, 2017.

CUNHA, Jorge Luiz da. Pesquisas com (auto)biografias: interfaces em tempos de individuação. In: PASSEGGI, Maria da Conceição; ABRAHÃO, Maria Helena Menna Barreto. (orgs.). Dimensões epistemológicas e metodológicas da pesquisa (auto)biográfica. Tomo I. Natal: EDUFRN; Porto Alegre: EDIPUCRS; Salvador: EDUNEB, 2012.

DELORY-MOMBERGER, Christine. A pesquisa biográfica: projeto epistemológico e perspectivas metodológicas. In: PASSEGI, Maria da Conceição; ABRAHÃO, Maria Helena Menna Barreto. (Orgs.). Dimensões epistemológicas e metodológicas da pesquisa (auto)biográfica. Tomo I. Natal: EDUFRN; Porto Alegre: EDIPUCRS; Salvador: EDUNEB, 2012.

DOMENICI, Eloisa. O encontro entre dança e educação somática como uma interface de questionamento epistemológico sobre as teorias do corpo. Pro-Posições, Campinas, v. 21, n. 2 (62), p. 69-85, maio/ago. 2010.

DOMINICÉ, Pierre. O processo de formação e alguns dos seus componentes relacionais. In: FINGER, Mathias; NÓVOA, António. O método (auto)biográfico e a formação. São Paulo: Paulus; Natal: EDUFRN, 2010.

EDYY, Martha. A brief history of somatic practices and dance: historical development of the field of somatic education and its relationship to dance. Journal of Dance and Somatic Practices. Coventry, v. 1, n. 1, 2009. 
ESPINOSA, Yuderkys. GÓMEZ, Diana. LUGONES, María. OCHOA, Karina. Reflexiones pedagógicas en torno al feminismo descolonial. In: WALSH, Catherine. Pedagogías decoloniales: práticas insurgentes de resistir, (re)existir y (re)vivier. Tomo I. Quito: Ediciones Abya-Yala, 2013. p.403-442.

FERNANDES, Ciane. O corpo em movimento: o sistema Laban/Bartenieff na formação e na pesquisa em artes cênicas. $2^{\mathrm{a}}$ Ed. São Paulo: Annablume, 2006.

FERREIRO, Emília. TEBEROSKY, Ana. Psicogênese da língua escrita. Porto Alegre: Artmed, 1999.

FERREIRO, Emília. Atualidade de Jean Piaget. Porto Alegre: Artmed Editora, 2001.

FORTIN, Sylvie. LONG, Walter. Percebendo diferenças no ensino e na aprendizagem de técnicas de dança contemporânea. Movimento em foco, Porto Alegre, v. 11, n. 2, p.9-29, maiago, 2005.

FORTIN, Sylvie. Living in movement. Development of somatics practices in different cultures. Journal of Dance Education. v. 2, n. 4, 2002.

FORTUNA, Tânia Ramos. Ludobiografia: uma invenção metodológica em pesquisa (auto)biográfica em educação. In: PASSEGI, Maria da Conceição; ABRAHÃO, Maria Helena Menna Barreto. (Orgs.). Dimensões epistemológicas e metodológicas dapesquisa (auto)biográfica. Tomo II. Natal: EDUFRN; Porto Alegre: EDIPUCRS; Salvador: EDUNEB, 2012. p. 165-202.

FREIRE, Paulo. Pedagogia da Autonomia: saberes necessários à prática educativa. São Paulo: Paz e Terra, 1996.

. Pedagogia do oprimido. $17^{\mathrm{a}}$ Ed. Rio de Janeiro: Paz e Terra, 1987.

GROSSI, Esther Pillar. Aspectos pedagógicos do construtivismo pós-piagetiano In: GROSSI, Esther Pillar. BORDINI, Jussara (org). Construtivismo pós-piagetiano. Petrópolis: Vozes, 1993.

JOLY, Yvan. L'Education somatique: au delà du discours de methodes 2002 Yvan Joly. Disponível em: 〈http://en.yvanjoly.com/images/f/fe/Educ_som_au-dela_du_disc-fr.pdf>. Acesso em 14 jul. 2015.

JOSSO, Marie-Christine. Experiências de vida e formação. São Paulo: Cortez, 2004.

HANNA, Thomas. The somatic healers and the somatic educator. In: SOMATICS: MagazineJournal of the Bodily Arts and Sciences. v. I, n. 3. 1977. Disponível em:

<http://somatics.org/library/htl-somatichealed.html >. Acesso em 02 fev. 2014.

. The field of somatics. SOMATICS: Magazine-Journal of the Bodily Arts and

Sciences, Volume I, No. 1, Outono 1976. 
LIMA, José Antônio. Educação somática: diálogos entre educação, saúde e arte no contexto da proposta da Reorganização Postural Dinâmica. 2010. 184 fls. Tese (Doutorado em Educação) - Faculdade de Educação, Universidade Estadual de Campinas, Campinas, 2010.

MARQUES, Isabel. Trajetórias do ensino da dança. In: MARQUES, Isabel. Ensino da dança hoje: textos e contextos. $4^{\mathrm{a}} \mathrm{Ed}$. São Paulo: Cortez, 2007.

MIGNOLO, Walter. VÁSQUEZ, Rolando. Pedagogía y (de)colonialidad. In: WALSH, Catherine. Pedagogías decoloniales: práticas insurgentes de resistir, (re)existir y (re)vivier. Tomo II. Quito: Ediciones Abya-Yala, 2017.

OLARTE, Rosana. El eterno aprendizaje del soma: análises de la Educación Somática y de la comunicación del movimiento en la danza. Cuadernos de música, artes visuales y artes escénicas. Bogotá, v. 3, n. 1, p. 105-159, out-mar, 2007.

OLIVEIRA, Valeska Fortes. A escrita como dispositivo na formação de professores. In: PERES, Lúcia Maria Vaz; ZANELLA, Andrisa Kemel. (Orgs.). Escritas de autobiografias educativas: o que dizemos e o que elas nos dizem? Curitiba: CRV, 2011.

PALERMO, Zulma. Irrupcion de saberes "otros" en el espacio pedagógico: hacia una “democracia decolonial” In: BORSANI, María Eugenia. QUINTERO, Pablo. (orgs.). Los desafios decoloniales de nuestros días: pensar en colectivo. Neuquén: Educo Editorial de la Universidad Nacional del Comahue, 2014.

PÉREZ, Carmen Lúcia Vidal. SAMPAIO, Carmen Sanches. Conversas sobre aprenderensinar a ler a escrever (nos) alfabetizando com crianças e sem cartilhas... In: LIBÂNEO, José Carlos. ALVES, Nilda (org). Temas de pedagogia: diálogos entre didática e currículo. São Paulo:

Cortez, 2012.

PIAGET, Jean. O nascimento da inteligência na criança. $4^{\mathrm{a}}$ Ed. Rio de Janeiro: LTC, 1987.

PULASKI, Mary Ann Spencer. Compreendendo Piaget: uma introdução ao desenvolvimento cognitivo da criança. Rio de Janeiro: LTC, 1986.

RAMOZZI -CHIAROTTINO, Zelia. Psicologia e epistemologia genética de Jean Piaget. São Paulo: EPU (Editora Pedagógica e Universitária Ltda), 1988.

RIBEIRO, Darcy. La universidad nueva: un proyecto. Caracas: Fundacion Biblioteca Ayacucho, 2006.

SANCHIS, Isabelle de Paiva; MAHFOUD, Miguel. Construtivismo: desdobramentos teóricos e no campo da educação. Revista Eletrônica de Educação. São Carlos, UFSCar, v.4, no. 1, p. 18-33, mai. 2010. 
Interação e construção: o sujeito e o conhecimento no construtivismo de Piaget.

Revista Ciências \& Cognição, 2007, v. 12. Disponível em:

$<\mathrm{http}$ ://www.cienciasecognicao.org/>. Acesso em: 18 jul. 2015.

SHAPIRO, Sherry. Em direção a professores transformadores: perspectivas feminista e crítica no ensino da dança. Pro-posições, Campinas, v. 9, n. 2, p. 35-53, jun. 1998.

SÖOT, Anu. VISKUS, Ele. Teaching dance in the $21^{\text {st }}$ century: A literature review. The European Journal of social\& Behavioural sciences, v. VII, 2013.

SANTOS, Boaventura de Sousa. Para além do Pensamento Abissal: das linhas globais a uma ecologia dos saberes. In: SANTOS, Boaventura de Sousa. MENESES, Maria Paula. (orgs). Epistemologias do Sul. Coimbra: Edições Almedina, 2009.

. Para uma sociologia das ausências e uma sociologia das emergências. Revista Crítica de Ciências Sociais, Coimbra, 63, p. 237-280, out. 2002.

STINSON, Susan. Uma pedagogia feminista para a dança da criança. Pro-posições, Campinas, v. 6, n. 3, 1995.

STRAZZACAPPA, Márcia. Educação somática: princípios e possíveis desdobramentos. Repertório - Teatro e Dança, Salvador, ano 12, número 13, p. 48-54, 2009.

VIANNA, Angel; CASTILHO, Jacyan. Percebendo o corpo. In: GARCIA, Regina Leite. (org). O corpo que fala dentro e fora da escola. Rio de Janeiro: DP\&A, 2002.

WALSH, Catherine. Introdução: Lo pedagógico y lo decolonial: Entretejiendo caminhos. In: WALSH, Catherine. (org). Pedagogías decoloniales: Prácticas insurgentes de resistir, (re)existir y (re)vivir. Tomo I. Quito: Ediciones Abya-Yala, 2013.

WOODRUFF, Dianne. Treinamento na dança: visões mecanicistas e holísticas. Cadernos do GIPE-CIT, Salvador, n. 2, p. 17-30, fev. 1999.

\footnotetext{
${ }^{\text {i }}$ Doutora em Artes Cênicas/UFBA e Professora Assistente do Curso de Licenciatura em Dança/UFSM.

ii [...] the students learn by imitating specific movement vocabularies modelled by an expert teacher" (SÖÖT; VISKUS, 2013, p. 1192).

iii Paulo Freire (1996, p. 24) afirma que: “Aprender precedeu o ensinar ou, em outras palavras, ensinar se diluía na experiência realmente fundante de aprender”. A partir dele, e apoiada em Carmen Lúcia Pérez e Carmen Sanches Sampaio (2012), utilizo o aprenderensinar juntos.

iv "Entendemos la decolonidad como el proceso por medio del cual re-conocemos otras historias, trayectorias y formas de ser y estar en el mundo, distintas a la lógica racional del capitalismo contemporáneo como expresión cultural (Jamenson, 1995; Zizek, 1998)" (ACHINTE, 2013, p. 452).

${ }^{\mathrm{V}}$ [...] la decolonialidad no es una teoría por seguir, sino un proyecto por asumir. Es un proceso accional para pedagógicamente andar" (WALSH, 2013, p. 67).

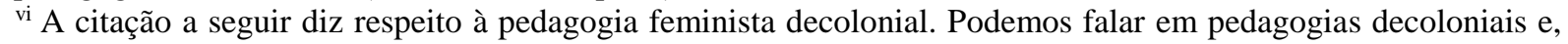
neste texto, acredito que o pensamento feminista decolonial dialoga com os conceitos de pedagogias decoloniais. Por isso a citação neste contexto, em que se fala da Educação Somática.
} 
vii "Esta pedagogía es una forma de conocer y hacer encarnada en los cuerpos individuales y colectivos, encarnada desde las experiencias subjetivas, corpóreas y emocionales de las mujeres que luchan. De esa manera integran lo que la modernidad a dicotomizado y jerarquizado: cuerpo y mente, emoción y razón, individualidad y colectividad se articulan para desde allí aprender y no sólo modificar los discursos sino las prácticas que hacen y deshacen los cuerpos" (ESPINOSA et al, 2013, 417).

viii "As dancers they were breaking rules; as people they were reintroducing non-Cartesian models" (EDDY, 2009, p. 10).

${ }^{\text {ix }}$ L'éducation somatique favorise la responsabilisation des individus et les accompagne dans une démarche d'autonomie, sur la base de l'expérience intime et personnelle que chaque personne a en tant que corps vivant." (REGROUPEMENT POUR L'EDUCACION SOMATIQUE. Disponível em: < http://education-somatique.ca/>. Acesso em: 4 mar 2014).

${ }^{x}$ L'éducation somatique favorise la responsabilisation des individus et les accompagne dans une démarche d'autonomie, sur la base de l'expérience intime et personnelle que chaque personne a en tant que corps vivant." (REGROUPEMENT POUR L'EDUCACION SOMATIQUE. Disponível em: 〈http://education-somatique.ca/>. Acesso em: 4 mar 2014).

xi "Cuando se percibe el mundo desde el cuerpo, el mundo ya no es un objeto a la mano, sino que uno es parte del mundo, nuestro cuerpo y nuestro devenir es mundo” (MIGNOLO; VÁSQUEZ, 2017, p. 499).

xii Alguns autores e autoras incluem os trabalhos de Vygotsky, Luria, Leontiev e Nuttin dentro do Construtivismo. Neste caso, dependendo do autor incluído, chamam de Construtivismo Sócio-Interacionista ou Construtivismo Sócio-Histórica.

xiii “[...] esta pedagogía hace posible es la producción de otro tipo de conocimiento mucho más cercano a las formas de aprendizaje y de producción de verdad asentadas en la cotidianidad y en las lógicas comunitarias y organizativas asentadas en una valoración de la experiencia vivida. [...] Se parte de la posibilidad de construir colectivamente desde el trueque de saberes y sabidurías que implica reconocer que todas y todos somos sabedores y productores de conocimiento" (ESPINOSA et al, 2013, p. 414).

xiv Paola Berestein Jacques (2008) chama de Corpografias urbanas uma cartografia realizada pelo e no corpo, a memória urbana inscrita no corpo, o registro da sua experiência da cidade. Aqui me refiro a corpografias as escritas e inscritas corporais como um todo, não apenas da cidade, como no caso da arquiteta. São também memórias corporais e o termo refere-se a estas escritas/inscritas, a partir do entendimento etimológico da palavra grafia (escrita).

xv "Las disciplinas privilegian la formación y escolarización disciplinaria sobre la educación de las personas (profesores y estudiantes). La pedagogia decolonial va en otra dirección. Enfatiza la emocionalidad sobre la racionalidad, la historia personal sobre los principios y métodos disciplinarios” (MIGNOLO; VÁSQUEZ, 2017, p. 496).

xvi “[...] nuestras interpretaciones del mundo y el orden instituido a través del ejercicio de rastrear los procesos mediante los cuales fueron impuestos determinados sentidos del mundo, mientras otros han sido sostenidamente desechados o invisibilizados [...]" (ESPINOSA et. al, 2013, p. 412).

${ }^{\text {xvii }} \mathrm{O}$ indiano Osho desenvolveu uma série de meditações que partiam do princípio do movimento, do chacoalhar e dançar até a exaustão para, posteriormente, ficar em silêncio.

xviii xviii “"[...] la producción del conocimiento no necesariamente es un acto individual, así como la academia no es el único lugar en donde este conocimiento se produce" (ACHINTE, 2014, p. 168).

xix "Pensar desde lo local, desde la pertenencia, es construir un lugar epistémico que incluya las diferencias, que reconozca a los silenciados más allá de los discursos que hablan en su nombre o que hacen del silencio una metáfora poética" (PALERMO, 2014, p.137).

xx “[...] no se ha formulado jamás, ni podrá formularse, un discurso definitivo y susceptible de aplicación universal” (RIBEIRO, 2006, p. 57). 